\title{
Pretransplant HbA1c Is a Useful Predictor for the Development of New-Onset Diabetes in Renal Transplant Recipients Receiving No or Low-Dose Erythropoietin
}

\author{
Kazuaki Tokodai, ${ }^{1,2}$ Noritoshi Amada, ${ }^{1}$ Izumi Haga, ${ }^{1}$ Atsushi Nakamura, ${ }^{1}$ \\ Toshiaki Kashiwadate, ${ }^{1}$ Naoki Kawagishi, ${ }^{2}$ and Noriaki Ohuchi ${ }^{2}$ \\ ${ }^{1}$ Department of Surgery, Sendai Shakaihoken Hospital, Sendai 980-8574, Japan \\ ${ }^{2}$ Division of Transplantation, Reconstruction and Endoscopic Surgery, Tohoku University Hospital, 1-1 Seiryo-machi, \\ Aoba-ku, Sendai 980-8574, Japan \\ Correspondence should be addressed to Kazuaki Tokodai; tsu7ka5so8mi@yahoo.co.jp
}

Received 30 March 2014; Revised 23 September 2014; Accepted 1 October 2014; Published 16 October 2014

Academic Editor: Muhammad Shahab

Copyright ( 2014 Kazuaki Tokodai et al. This is an open access article distributed under the Creative Commons Attribution License, which permits unrestricted use, distribution, and reproduction in any medium, provided the original work is properly cited.

\begin{abstract}
Aims. To evaluate the predictive power of pretransplant HbAlc for new-onset diabetes after transplantation (NODAT) in kidney transplant candidates, who had several predispositions for fluctuated HbAlc levels. Methods. We performed a retrospective study of 119 patients without diabetes who received kidney transplantation between March 2000 and January 2012. Univariate and multivariate logistic regression analyses were used to investigate the association of several parameters with NODAT. Predictive discrimination of $\mathrm{HbAlc}$ was assessed using a receiver-operating characteristic curve. Results. Seventeen patients (14.3\%) developed NODAT within 1 year of transplantation. Univariate logistic regression analysis revealed that recipient age, gender, and $\mathrm{HbAlc}$ were predictors of NODAT. In the multivariate analysis, the association between pretransplant HbAlc and NODAT development did not reach statistical significance $(P=0.07)$. To avoid the strong influence of high-dose erythropoietin on HbAlc levels, we performed subgroup analyses on 85 patients receiving no or low-dose ( $\leq 6000 \mathrm{IU} /$ week) erythropoietin. HbAlc was again an independent predictor for NODAT. Receiver-operating characteristic analysis revealed a cut-off value of $5.2 \%$ with an optimal sensitivity of $64 \%$ and specificity of $78 \%$ for predicting NODAT. Conclusions. Our results reveal that the pretransplant HbAlc level is a useful predictor for NODAT in patients receiving no or low-dose erythropoietin.
\end{abstract}

\section{Introduction}

A serious and frequent complication of transplantationnew-onset diabetes after transplantation (NODAT) - is associated with increased cardiovascular morbidity and mortality that is observed in kidney transplant patients $[1,2]$ as well as with decreased graft and patient survival [3-5]. Thus, pretransplant identification of patients at high risk of developing NODAT would be greatly advantageous by enabling the modification of NODAT by the use of less diabetogenic immunosuppressive drugs or implementation of lifestylechange interventions. Several clinical trials have revealed that lifestyle-change interventions were effective in preventing type 2 diabetes mellitus $[6,7]$ and that they may be applicable in NODAT cases too. We previously reported that the posttransplant increase in body mass index and body fat percentage is associated with the development of NODAT $[8,9]$, indicating that lifestyle-change interventions are useful for preventing NODAT.

The postload plasma glucose level during an oral glucose tolerance test (OGTT) is a strong predictor for the development of diabetes in the future [10,11]. Furthermore, we have recently reported that OGTT can be a useful predictor of NODAT development [12]. However, OGTT is time consuming and forces patients to fast overnight. HbAlc is much easier to test and examine than OGTT and has been increasingly used for assessing chronic glycemia in patients with diabetes, diagnosing diabetes mellitus, and identifying those who may 


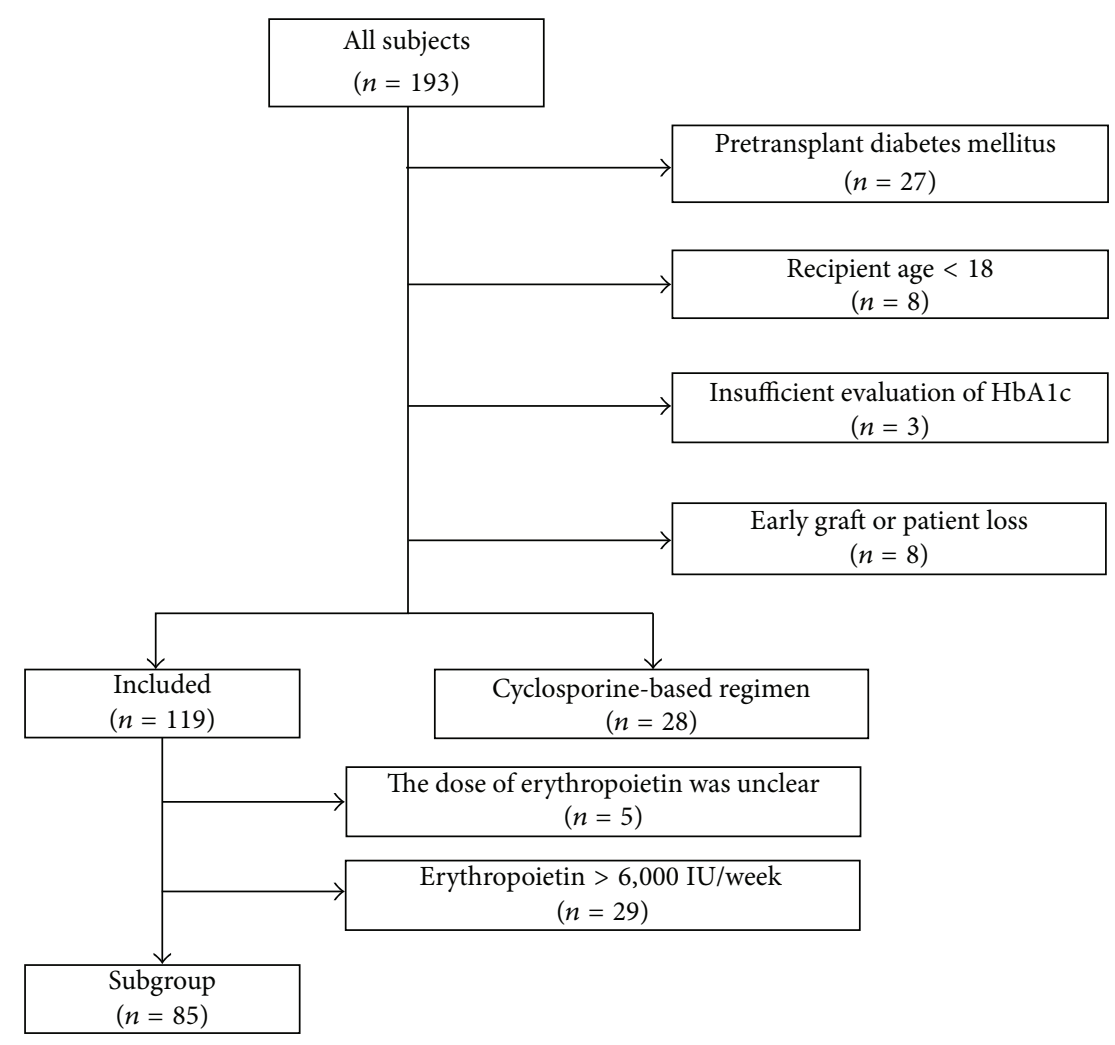

Figure 1: Flowchart of patient enrollment.

be at high risk for developing diabetes in the future [13-16]. Furthermore, several studies showed the efficacy of HbAlc in the detection of posttransplant diabetes mellitus [17-19]. However, HbAlc values are strongly influenced by anemia and erythropoietin (EPO) treatment [20-22]. Further, kidney transplant candidates are frequently administered EPO injections for the treatment of anemia; hence, the pretransplant HbAlc level should be cautiously interpreted. Although Tatar et al. showed that the pretransplant HbAlc level can be used to identify the high-risk group of NODAT [23], the utility of $\mathrm{HbA1c}$ as a predictor for the development of NODAT has not been completely elucidated.

In our previous study, all patients who developed NODAT had received tacrolimus-based immunosuppressive treatment [8]. Hence, in this study, we evaluated the predictive power of the pretransplant HbAlc level for the development of NODAT in patients receiving tacrolimus-based immunosuppressive treatment.

\section{Patients and Methods}

2.1. Patient Selection. We retrospectively identified 193 consecutive patients who received living donor kidney transplants in our hospital between March 2000 and January 2012. Seventy-four patients were excluded from this study for the following reasons: pretransplant diabetes mellitus $(n=27)$, recipient age $<18$ years $(n=8)$, insufficient data on HbAlc $(n=3)$, early graft or patient loss $(n=8)$, and cyclosporinebased immunosuppressive regimen $(n=28)$. Pretransplant diabetes was defined as the use of insulin or oral antihyperglycemic medications or fasting plasma glucose levels $\geq 126 \mathrm{mg} / \mathrm{dL}$. Finally, a total of 119 patients were included in this study (Figure 1). For subgroup analysis, we identified 85 patients receiving no or low-dose $(\leq 6,000 \mathrm{IU} /$ week) EPO. To avoid detection bias, systematic, standardized, and periodic examinations of posttransplant glucose tolerance were performed on all patients regardless of pretransplant HbAlc levels. HbAlc was measured basically within 3 months prior to transplantation by high performance liquid chromatography (HPLC) method and estimated as a National Glycohemoglobin Standardization Program (NGSP) value. The HbAlc (Japan Diabetes Society (JDS)) was converted to HbAlc (NGSP) using the officially certified equation: NGSP $(\%)=1.02 \times \mathrm{JDS}(\%)+0.25 \%[24]$. The clinical data were collected retrospectively from the hospital data system and from clinical records in August 2013. The local institutional internal review board approved this study.

2.2. Immunosuppressive Regimens. Patients received immunosuppressive treatment consisting of prednisolone, tacrolimus, mycophenolate mofetil or mizoribine, and basiliximab. Prednisolone was started at $1 \mathrm{mg} / \mathrm{kg}$ with subsequent tapering to $0.2 \mathrm{mg} / \mathrm{kg} 1 \mathrm{month}$ after transplantation. Tacrolimus was initiated 2 days before transplantation and adjusted to maintain the initial trough level of $10-12 \mathrm{ng} / \mathrm{mL}$ and the long-term target trough level of 6-8 ng/mL. Mycophenolate mofetil or mizoribine was started on the day after transplantation. Basiliximab $20 \mathrm{mg}$ was administered intravenously on days 0 and 
TABLE 1: Comparison of patients who developed NODAT ${ }^{\mathrm{a}}$ (NODAT+) to those who did not (NODAT-).

\begin{tabular}{|c|c|c|c|}
\hline Variable & $\begin{array}{c}\text { NODAT+ } \\
(n=17)\end{array}$ & $\begin{array}{c}\text { NODAT- } \\
(n=102)\end{array}$ & $P$ value \\
\hline Recipient age [y] & $47.5(10.5)$ & $38.7(11.7)$ & $<0.005$ \\
\hline Recipient gender (M/F) & $(15 / 2)$ & $(64 / 38)$ & 0.05 \\
\hline Donor age $[y]$ & $53.4(7.9)$ & $55.6(10.2)$ & 0.38 \\
\hline Donor gender $(\mathrm{M} / \mathrm{F})$ & $(4 / 13)$ & $(36 / 66)$ & 0.42 \\
\hline Fasting plasma glucose $[\mathrm{mg} / \mathrm{dL}]$ & $82.9(6.9)$ & $80.1(9.0)$ & 0.22 \\
\hline HbAlc $[\%]$ & $5.2(0.45)$ & $4.9(0.45)$ & $<0.05$ \\
\hline Hemoglobin $[\mathrm{g} / \mathrm{L}]$ & $10.6(2.4)$ & $10.4(1.8)$ & 0.60 \\
\hline $\mathrm{EPO}^{\mathrm{b}}$ (none/low-dose $\mathrm{c}^{\mathrm{c}} /$ high-dose $^{\mathrm{d}}$ ) & $(1 / 11 / 4)$ & $(15 / 59 / 25)$ & 0.74 \\
\hline Cause of chronic renal failure & & & 0.50 \\
\hline Glomerulonephritis & $13(76 \%)$ & $62(61 \%)$ & \\
\hline Polycystic kidney disease & $0(0 \%)$ & $4(4 \%)$ & \\
\hline Hypertension/nephrosclerosis & $1(6 \%)$ & $4(4 \%)$ & \\
\hline Other/unknown & $3(18 \%)$ & $32(31 \%)$ & \\
\hline Pretransplant $\mathrm{BMI}^{\mathrm{e}}$ & $21.1(2.6)$ & $21.2(3.1)$ & 0.95 \\
\hline Dialysis period $[\mathrm{mo}]$ & $24(0-171)$ & $15(0-198)$ & 0.23 \\
\hline Hepatitis C positive & $2(12 \%)$ & $1(1 \%)$ & 0.05 \\
\hline ABO incompatible & $3(18 \%)$ & $15(15 \%)$ & 0.72 \\
\hline
\end{tabular}

New-onset diabetes after transplantation.

${ }^{\mathrm{b}}$ Erythropoietin.

${ }^{c} 0<\mathrm{EPO} \leq 6,000 \mathrm{IU} /$ week.

${ }^{\mathrm{d}} \mathrm{EPO}>6,000 \mathrm{IU} /$ week.

${ }^{\mathrm{e}}$ Body mass index $\left[\mathrm{kg} / \mathrm{m}^{2}\right]$.

4. Acute rejection was confirmed by graft biopsy and treated with intravenous methylprednisolone ( 250 or $125 \mathrm{mg} /$ day) for 3 days followed by deoxyspergualin $5 \mathrm{mg} /[\mathrm{kg}$. day] for 5 days.

2.3. Definition of NODAT. NODAT was defined according to the American Diabetes Association [25] as the presence of diabetes symptoms in addition to casual plasma glucose levels $\geq 200 \mathrm{mg} / \mathrm{dL}$ or fasting plasma glucose levels $\geq 126 \mathrm{mg} / \mathrm{dL}$. Fasting was defined as the absence of caloric intake for at least $8 \mathrm{~h}$. In this study, patients with transient elevations of fasting plasma glucose levels immediately after transplantation or during times of acute illness were not diagnosed with NODAT. Patients who presented with impaired fasting glucose were introduced to diabetologists for further examinations. Patients who started to receive insulin or oral antihyperglycemic medications after transplantation were also diagnosed as NODAT.

2.4. EPO Injection. All doses of EPO were presented as recombinant human EPO per week. For the conversion of darbepoetin alfa dosage to recombinant human EPO, a ratio of $1 \mu \mathrm{g}$ darbepoetin alfa to $200 \mathrm{IU}$ recombinant human EPO ratio was used [26]. Recombinant EPO is generally used with a dose of $4,500,6,000$, or $9,000 \mathrm{IU} /$ week. In this study, low-dose and high-dose EPO were defined as $0<$ EPO $\leq$ 6,000 IU/week and EPO > 6,000 IU/week, respectively.
2.5. Statistical Analysis. Data are expressed as means ( \pm standard deviation) or median (range) as appropriate. Statistical significance was determined using Student's $t$-test for normally distributed data, Wilcoxon's signed rank test for skewed data, and Fisher's exact test for dichotomous data. Univariate and multivariate logistic regression analyses were used to assess the association of several parameters with the incidence of NODAT. Predictive discrimination of HbAlc was assessed using a receiver-operating characteristic (ROC) curve on the basis of maximizing sensitivity and specificity. Analyses were performed using JMP Pro 10 (SAS Institute, Cary, NC). A value of $P<0.05$ was considered significant.

\section{Results}

3.1. Patient Demographics. The baseline data of the patients who did and did not develop NODAT are presented in Table 1. Of the 119 patients included in this study, 17 patients (14.3\%) developed NODAT within 1 year of transplantation. Patients who developed NODAT were significantly older than those who did not develop NODAT. There were no differences in donor age, gender, cause of chronic renal failure, or pretransplant body mass index.

3.2. Predictors of NODAT. Univariate logistic regression analysis showed that recipient age, gender, and HbAlc were 
TABLE 2: Risk factors for NODAT ${ }^{\mathrm{a}}$ : univariate and multivariate analyses.

\begin{tabular}{|c|c|c|c|c|c|c|}
\hline \multirow{2}{*}{ Variable } & \multicolumn{3}{|c|}{ Univariate analysis } & \multicolumn{3}{|c|}{ Multivariate analysis } \\
\hline & $\mathrm{OR}^{\mathrm{b}}$ & $95 \% \mathrm{CI}^{\mathrm{c}}$ & $P$ value & OR & $95 \%$ CI & $P$ value \\
\hline Recipient age [y] & 1.05 & $1.02-1.12$ & $<0.005$ & 1.06 & $1.01-1.12$ & $<0.05$ \\
\hline Recipient gender & 4.45 & $1.17-29.2$ & $<0.05$ & 4.10 & $0.99-28.5$ & 0.05 \\
\hline Donor age $[y]$ & 0.98 & $0.93-1.03$ & 0.39 & & & \\
\hline Pretransplant $\mathrm{BMI}^{\mathrm{d}}$ & 0.98 & $0.83-1.17$ & 0.95 & & & \\
\hline $\mathrm{FPG}^{\mathrm{e}}[\mathrm{mg} / \mathrm{dL}]$ & 1.04 & $0.98-1.10$ & 0.23 & & & \\
\hline HbAlc [\%] & 3.99 & $1.34-12.8$ & $<0.05$ & 3.09 & $0.90-11.1$ & 0.07 \\
\hline Dialysis period [mo] & 1.01 & $0.99-1.02$ & 0.26 & & & \\
\hline
\end{tabular}

${ }^{a} \mathrm{New}$-onset diabetes after transplantation.

${ }^{\mathrm{b}}$ Odds ratio.

${ }^{\mathrm{c}} 95 \%$ confidence interval.

${ }^{\mathrm{d}}$ Body mass index $\left[\mathrm{kg} / \mathrm{m}^{2}\right]$.

${ }^{\mathrm{e}}$ Fasting plasma glucose.

TABLE 3: Risk factors for NODAT ${ }^{\mathrm{a}}$ in patients receiving $\mathrm{EPO}^{\mathrm{b}} \leq 6,000 \mathrm{IU} /$ week: multivariate analysis.

\begin{tabular}{|c|c|c|c|c|c|c|}
\hline \multirow{2}{*}{ Variable } & \multicolumn{3}{|c|}{ Univariate analysis } & \multicolumn{3}{|c|}{ Multivariate analysis } \\
\hline & $\mathrm{OR}^{\mathrm{c}}$ & $95 \% \mathrm{CI}^{\mathrm{d}}$ & $P$ value & OR & $95 \%$ CI & $P$ value \\
\hline Recipient age [y] & 1.05 & $0.99-1.11$ & 0.10 & 1.05 & $0.99-1.13$ & 0.09 \\
\hline Recipient gender & 2.59 & $0.61-17.8$ & 0.21 & 3.91 & $0.75-33.8$ & 0.11 \\
\hline Donor age [y] & 0.96 & $0.91-1.03$ & 0.24 & & & \\
\hline Pretransplant $\mathrm{BMI}^{\mathrm{e}}$ & 0.98 & $0.76-1.24$ & 0.84 & & & \\
\hline $\mathrm{FPG}^{\mathrm{f}}[\mathrm{mg} / \mathrm{dL}]$ & 1.02 & $0.94-1.09$ & 0.68 & & & \\
\hline HbAlc [\%] & 8.32 & $1.74-47.2$ & $<0.01$ & 9.18 & $1.64-64.5$ & $<0.05$ \\
\hline Dialysis period [mo] & 1.01 & $0.99-1.02$ & 0.33 & & & \\
\hline
\end{tabular}

${ }^{a}$ New-onset diabetes after transplantation.

${ }^{\mathrm{b}}$ Erythropoietin.

${ }^{\mathrm{c}}$ Odds ratio.

$\mathrm{d}_{95 \%}$ confidence interval.

${ }^{\mathrm{e}}$ Body mass index $\left[\mathrm{kg} / \mathrm{m}^{2}\right]$.

${ }^{\mathrm{f}}$ Fasting plasma glucose.

significant predictors for the development of NODAT. In the multivariate analysis, only the recipient age was an independent predictor of NODAT. The association between the pretransplant HbAlc level and development of NODAT did not reach statistical significance $(P=0.07)$, after adjusting for recipient age and gender, the 2 factors of $P<0.05$ (Table 2 ).

3.3. Subgroup Analyses for the Patients Receiving No or LowDose EPO. For 29 of the 119 patients included in this study, EPO doses were > 6,000 IU/week; the EPO doses of 5 patients were not available. Therefore, these 34 patients were excluded from the subgroup analyses of patients receiving no or lowdose EPO. Of the 85 patients that were included, 11 patients (12.9\%) developed NODAT. Multivariate logistic regression subanalysis revealed that the pretransplant HbAlc level was an independent predictor for the development of NODAT (Table 3). The ROC analyses showed that the area under the ROC curve was 0.75 and the cut-off level of HbAlc which gave the maximum sensitivity and specificity was $5.2 \%$ (Figure 2). The sensitivity, specificity, positive predictive

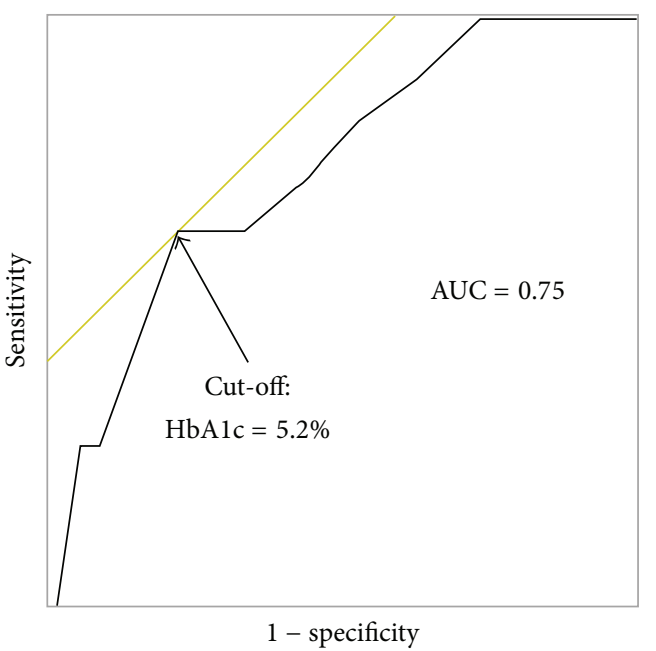

FIGURE 2: The receiver-operating characteristic curve of pretransplant HbAlc. The cut-off point of the HbAlc level was 5.2\%, which was derived on the basis of maximizing sensitivity and specificity. AUC: area under the receiver-operating characteristic curve. 
TABLE 4: Sensitivity, specificity, positive predictive value, negative predictive value, and likelihood ratio of HbAlc for several cut-off values.

\begin{tabular}{lccccc}
\hline HbAlc & 4.8 & 5.0 & 5.2 & 5.4 & 5.6 \\
\hline Sensitivity & 91 & 73 & 64 & 45 & 27 \\
Specificity & 36 & 57 & 78 & 85 & 92 \\
Positive predictive value & 18 & 20 & 30 & 31 & 33 \\
Negative predictive value & 96 & 93 & 94 & 91 & 89 \\
Likelihood ratio & 0.21 & 0.25 & 0.44 & 0.45 & 0.5 \\
\hline
\end{tabular}

value, and negative predictive value of $\mathrm{HbAlc}$ at the cut-off point were $64 \%, 78 \%, 30 \%$, and $94 \%$, respectively (Table 4 ).

\section{Discussion}

In this study, we found that even in patients with chronic renal failure, who had several predispositions for fluctuated HbAlc levels, pretransplant HbAlc was associated with NODAT development; moreover, pretransplant HbAlc levels were an independent predictor of NODAT development in patients receiving no or low-dose EPO. Our subgroup analysis further revealed that the cut-off value for HbAlc was $5.2 \%$ and indicated that the risk of NODAT development was significantly higher in patients with HbAlc levels above this cut-off.

Pretransplant $\mathrm{HbAlc}$ levels were a significant predictor of NODAT for patients receiving no or low-dose EPO; however, this association was not observed during the whole group analysis. This inconsistency might be due to a high degree of variability in $\mathrm{HbAlc}$ levels in patients receiving high-dose EPO. Uzu et al. reported that high-dose EPO strongly influenced HbAlc levels [27], and therefore pretransplant HbAlc levels might be difficult to apply to these patients.

Our study has several points in common with those of a study by Tatar et al. that revealed the predictive value of pretransplant $\mathrm{HbAlc}$ for NODAT development within 1 year after kidney transplantation. Both the studies excluded recipients aged $<18$ years and included recipients with similar baseline characteristics, including equivalent age, sex, and pretransplant HbAlc level. The major difference between these two studies was the study design: our study excluded patients who had received a cyclosporine-based immunosuppressive regimen because our previous study had showed that all patients who developed NODAT had received a tacrolimusbased immunosuppressive regimen [12]. Furthermore, in our study, the incidence rate of NODAT development was lower (14.3\%) than that in Tatar's study (25.9\%), and pretransplant BMI and fasting plasma glucose levels were not associated with NODAT development. These inconsistencies might be due to the difference in race, considering that all the included patients in our study were Japanese with low BMIs. A weakness of our study is that the predictive value of pretransplant HbAlc was determined only for the subgroup patients who did not receive EPO or patients who received only low-dose EPO. However, we believe that this point is also an original strong point of our study because most of the kidney transplant candidates received EPO therapies, and pretransplant HbAlc level should be interpreted after considering the EPO dose.

The cut-off point of $5.2 \%$, which was derived by the subgroup analysis on the basis of maximizing sensitivity and specificity, was considered clinically acceptable, because it could identify the low- and high-risk groups with reasonable predictive values as a predictor of short-term NODAT development. The risk of NODAT development in patients receiving no or low-dose EPO with an $\mathrm{HbAlc} \geq 5.2 \%$ was 6.34 -fold higher than in patients with an $\mathrm{HbAlc}<5.2 \%$, which is higher than the reported odds ratio of impaired glucose tolerance based on a OGTT [28]. According to the American Diabetes Association, prediabetes is defined as $5.7 \% \leq \mathrm{HbAlc} \leq 6.4 \%$ in the general population [13]. The cut-off value derived from this study was lower than that for the general population, which is most likely due to the influence of EPO; this is consistent with reports suggesting that the target $\mathrm{HbAlc}$ level should be lowered to $5.1 \%$ for patients with hematocrit $<30$ and EPO $\geq 100 \mathrm{IU} /[\mathrm{kg} \cdot w e e k]$ [27]. The AUC of 0.75, sensitivity of $64 \%$, and specificity of $78 \%$ compare favorably with previously reported values in the general population [15], indicating that HbAlc values are indeed useful and can be applied to clinical practices in transplant settings, although the cut-off level of $5.2 \%$ needs to be further evaluated.

Although several reports suggest that the HbAlc level can be interpreted after using a correction formula ( $\mathrm{HbAlc} *$ 1.19 in those with low EPO dosages, i.e., $<100 \mathrm{IU} /[\mathrm{kg} \cdot w e e k]$, and HbAlc $* 1.38$ in those with high EPO dosages, i.e., $\geq 100 \mathrm{IU} /[\mathrm{kg} \cdot w e e \mathrm{k}]$ ) [27], this formula is complicated to use in the clinical setting, as it requires clinicians to calculate the corrected HbAlc value each time. This formula is even less practical with regard to recently developed EPO drugs that have a longer elimination half-life because the dosage for these new drugs must first be converted into the comparable recombinant human EPO dose before the correction formula can be applied. In this study, 29 out of a total of 119 patients received high-dose EPO (>6,000 IU/week) therapy. By excluding this minority group, pretransplant $\mathrm{HbAlc}$ was an independent predictor for NODAT in the subgroup multivariate analysis. These results indicate that the pretransplant HbAlc level, which has been considered difficult to interpret in patients with chronic renal failure, can be used as a useful predictor of NODAT by excluding patients receiving maximum dose EPO.

The uremic state was also a well-known factor to affect the HbAlc levels measured by HPLC method. Carbamylated hemoglobin, which was greatly elevated in uremia, was significantly correlated with chromatographically determined glycosylated hemoglobin [29]. Indeed, HbAlc levels measured by HPLC should be interpreted with much caution in uremia. On the other hand, Smith et al. also reported that hemodialysis had no effect on the HbAlc levels measured by HPLC although the slight increases were observed in the settings of chronic renal failure and continuous ambulatory peritoneal dialysis [29]. Furthermore, HbAlc values measured by HPLC have been widely utilized for patients with chronic renal failure $[22,27]$ and shown to be associated with increased death risk in the patients undergoing maintenance 
hemodialysis [30, 31]. Based on these results, we believe that HbAlc can be a useful tool even for patients with uremia.

In this study, fasting plasma glucose levels were comparable between the groups, whereas in the study by Tatar et al., pretransplant fasting blood glucose levels were reported as an independent predictor of NODAT development [23]. As the predictive value of fasting plasma glucose for the development of type 2 diabetes remains controversial [32, 33], its predictive value for NODAT development needs to be further investigated. Hepatitis $\mathrm{C}$ virus (HCV) infection is also an important risk factor of the development of type 2 diabetes, as we have previously reported [12]. In this study, however, only 3 of the 119 patients had HCV infections; hence, the association between HCV infections and NODAT development could not be statistically investigated.

Our study has several limitations. This was a retrospective single-center study, and the sample size was small. Because of the small sample size, the predictive power of HbAlc according to the EPO dose could not be fully compared. For the same reason, we could not fully assess the utility of $\mathrm{HbAlc}$ in patients receiving high-dose EPO. Furthermore, we could not compare the efficacy of HbAlc with that of other indexes such as oral glucose tolerance tests. However, we believe that pretransplant $\mathrm{HbAlc}$ levels are easy to obtain and can be a useful tool to identify patients at high risk for the development of NODAT.

Our results reveal that the pretransplant $\mathrm{HbAlc}$ level is an important predictor for the development of NODAT for patients receiving EPO doses of $\leq 6,000 \mathrm{IU} /$ week. There are several restrictions for the use of the HbAlc level as a predictor of NODAT before kidney transplantation, especially in patients receiving high-dose EPO treatment. In the future, longer-term prospective studies with larger sample sizes should be conducted to confirm our findings and examine the use of the pretransplant HbAlc level for patients receiving high-dose EPO. The clinical impact of improving the identification of patients at high risk of developing NODAT prior to transplantation is high, as it would allow for the individual adaptation of immunosuppressive treatments and implementation of lifestyle-change interventions.

\section{Conflict of Interests}

The authors declare that there is no conflict of interests regarding the publication of this paper.

\section{References}

[1] J. Hjelmesæth, A. Hartmann, T. Leivestad et al., "The impact of early-diagnosed new-onset post-transplantation diabetes mellitus on survival and major cardiac events," Kidney International, vol. 69, no. 3, pp. 588-595, 2006.

[2] B. L. Kasiske, "Epidemiology of cardiovascular disease after renal transplantation,” Transplantation, vol. 72, no. 6, pp. S5-S8, 2001.

[3] B. L. Kasiske, J. J. Snyder, D. Gilbertson, and A. J. Matas, "Diabetes mellitus after kidney transplantation in the United States," The American Journal of Transplantation, vol. 3, no. 2, pp. 178$185,2003$.
[4] F. G. Cosio, T. E. Pesavento, S. Kim, K. Osei, M. Henry, and R. M. Ferguson, "Patient survival after renal transplantation: IV. Impact of post-transplant diabetes," Kidney International, vol. 62, no. 4, pp. 1440-1446, 2002.

[5] V. K. Revanur, A. G. Jardine, D. B. Kingsmore, B. C. Jaques, D. H. Hamilton, and R. M. Jindal, "Influence of diabetes mellitus on patient and graft survival in recipients of kidney transplantation," Clinical Transplantation, vol. 15, no. 2, pp. 8994, 2001.

[6] J. Tuomilehto, J. Lindström, J. G. Eriksson et al., "Prevention of type 2 diabetes mellitus by changes in lifestyle among subjects with impaired glucose tolerance," The New England Journal of Medicine, vol. 344, no. 18, pp. 1343-1350, 2001.

[7] W. C. Knowler, E. Barrett-Connor, S. E. Fowler et al., "Reduction in the incidence of type 2 diabetes with lifestyle intervention or metformin," The New England Journal of Medicine, vol. 346, no. 6, pp. 393-403, 2002.

[8] K. Tokodai, N. Amada, H. Kikuchi, I. Haga, T. Takayama, and A. Nakamura, "Posttransplant increase of body mass index is associated with new-onset diabetes mellitus after kidney transplantation," Tohoku Journal of Experimental Medicine, vol. 229, no. 3, pp. 227-232, 2013.

[9] K. Tokodai, N. Amada, H. Kikuchi, I. Haga, T. Takayama, and A. Nakamura, "Body fat percentage as a marker of new-onset diabetes mellitus after kidney transplantation," Transplantation Proceedings, vol. 45, no. 4, pp. 1544-1547, 2013.

[10] N. Unwin, J. Shaw, P. Zimmet, and K. G. M. M. Alberti, "Impaired glucose tolerance and impaired fasting glycaemia: the current status on definition and intervention," Diabetic Medicine, vol. 19, no. 9, pp. 708-723, 2002.

[11] K. J. Joshipura, M. O. Andriankaja, F. B. Hu, and C. S. Ritchie, "Relative utility of 1-h Oral Glucose Tolerance Test as a measure of abnormal glucose homeostasis," Diabetes Research and Clinical Practice, vol. 93, no. 2, pp. 268-275, 2011.

[12] K. Tokodai, N. Amada, I. Haga, T. Takayama, and A. Nakamura, "The 5-time point oral glucose tolerance test as a predictor of new-onset diabetes after kidney transplantation," Diabetes Research and Clinical Practice, vol. 103, no. 2, pp. 298-303, 2014.

[13] "Diagnosis and classification of diabetes mellitus," Diabetes Care, vol. 33, supplement 1, pp. S62-S69, 2010.

[14] The International Expert Committee, "International Expert Committee report on the role of the A1C assay in the diagnosis of diabetes," Diabetes Care, vol. 32, no. 7, pp. 1327-1334, 2009.

[15] C. Droumaguet, B. Balkau, D. Simon et al., "Use of HbAlc in predicting progression to diabetes in French men and women: data from an Epidemiological Study on the Insulin Resistance Syndrome (DESIR)," Diabetes Care, vol. 29, no. 7, pp. 1619-1625, 2006.

[16] K. Inoue, M. Matsumoto, and K. Akimoto, "Fasting plasma glucose and $\mathrm{HbA}_{1 c}$ as risk factors for Type 2 diabetes," Diabetic Medicine, vol. 25, no. 10, pp. 1157-1163, 2008.

[17] R. Hoban, B. Gielda, M. Temkit et al., "Utility of HbA1c in the detection of subclinical post renal transplant diabetes," Transplantation, vol. 81, no. 3, pp. 379-383, 2006.

[18] S. Shabir, S. Jham, L. Harper, S. Ball, R. Borrows, and A. Sharif, "Validity of glycated haemoglobin to diagnose new onset diabetes after transplantation," Transplant International, vol. 26, no. 3, pp. 315-321, 2013.

[19] T. G. Valderhaug, T. Jenssen, A. Hartmann et al., "Fasting plasma glucose and glycosylated hemoglobin in the screening for diabetes mellitus after renal transplantation," Transplantation, vol. 88 , no. 3, pp. 429-434, 2009. 
[20] J. M. Ng, P. E. Jennings, P. Laboi, and V. Jayagopal, "Erythropoetin treatment significantly alters measured glycated haemoglobin (HbAlc)," Diabetic Medicine, vol. 25, no. 2, pp. 239-240, 2008.

[21] J. M. Ng, M. Cooke, S. Bhandari, S. L. Atkin, and E. S. Kilpatrick, "The effect of iron and erythropoietin treatment on the A1C of patients with diabetes and chronic kidney disease," Diabetes Care, vol. 33, no. 11, pp. 2310-2313, 2010.

[22] T. Nakao, H. Matsumoto, T. Okada et al., "Influence of erythropoietin treatment on hemoglobin $\mathrm{A}(1 \mathrm{c})$ levels in patients with chronic renal failure on hemodialysis," Internal Medicine, vol. 37, no. 10, pp. 826-830, 1998.

[23] E. Tatar, F. Kircelli, M. S. Demirci et al., "Pre-transplant $\mathrm{HbA}_{1 c}$ level as an early marker for new-onset diabetes after renal transplantation," International Urology and Nephrology, vol. 45, no. 1, pp. 251-258, 2013.

[24] A. Kashiwagi, M. Kasuga, E. Araki et al., "International clinical harmonization of glycated hemoglobin in Japan: from Japan Diabetes Society to National Glycohemoglobin Standardization Program values," Journal of Diabetes Investigation, vol. 3, no. 1, pp. 39-40, 2012.

[25] American Diabetes Association, "Diagnosis and classification of diabetes mellitus," Diabetes Care, vol. 27, supplement 1, pp. S5-S10, 2004.

[26] F. Locatelli, B. Canaud, F. Giacardy, A. Martin-Malo, N. Baker, and J. Wilson, "Treatment of anaemia in dialysis patients with unit dosing of darbepoetin alfa at a reduced dose frequency relative to recombinant human erythropoietin (rHuEpo)," Nephrology Dialysis Transplantation, vol. 18, pp. 362-369, 2003.

[27] T. Uzu, T. Hatta, N. Deji et al., "Target for glycemic control in type 2 diabetic patients on hemodialysis: effects of anemia and erythropoietin injection on hemoglobin $\mathrm{A}_{1 c}$, "Therapeutic Apheresis and Dialysis, vol. 13, no. 2, pp. 89-94, 2009.

[28] S. Iida, H. Ishida, T. Tokumoto et al., "New-onset diabetes after transplantation in tacrolimus-treated, living kidney transplantation: long-term impact and utility of the pre-transplant OGTT," International Urology and Nephrology, vol. 42, no. 4, pp. 935-945, 2010.

[29] W. G. J. Smith, M. Holden, M. Benton, and B. Brown, "Glycosylated and carbamylated haemoglobin in uraemia," Nephrology Dialysis Transplantation, vol. 4, no. 2, pp. 96-100, 1989.

[30] K. Kalantar-Zadeh, J. D. Kopple, D. L. Regidor et al., "A1C and survival in maintenance hemodialysis patients," Diabetes Care, vol. 30, no. 5, pp. 1049-1055, 2007.

[31] J. Ricks, M. Z. Molnar, C. P. Kovesdy et al., "Glycemic control and cardiovascular mortality in hemodialysis patients with diabetes: a 6-year cohort study," Diabetes, vol. 61, no. 3, pp. 708715, 2012.

[32] M. A. Abdul-Ghani, M. P. Stern, V. Lyssenko, T. Tuomi, L. Groop, and R. A. DeFronzo, "Minimal contribution of fasting hyperglycemia to the incidence of type 2 diabetes in subjects with normal 2-h plasma glucose," Diabetes Care, vol. 33, no. 3, pp. 557-561, 2010.

[33] K. Inoue, M. Matsumoto, and Y. Kobayashi, “The combination of fasting plasma glucose and glycosylated hemoglobin predicts type 2 diabetes in Japanese workers," Diabetes Research and Clinical Practice, vol. 77, no. 3, pp. 451-458, 2007. 


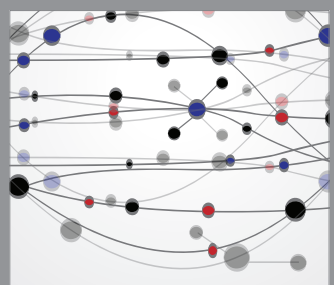

The Scientific World Journal
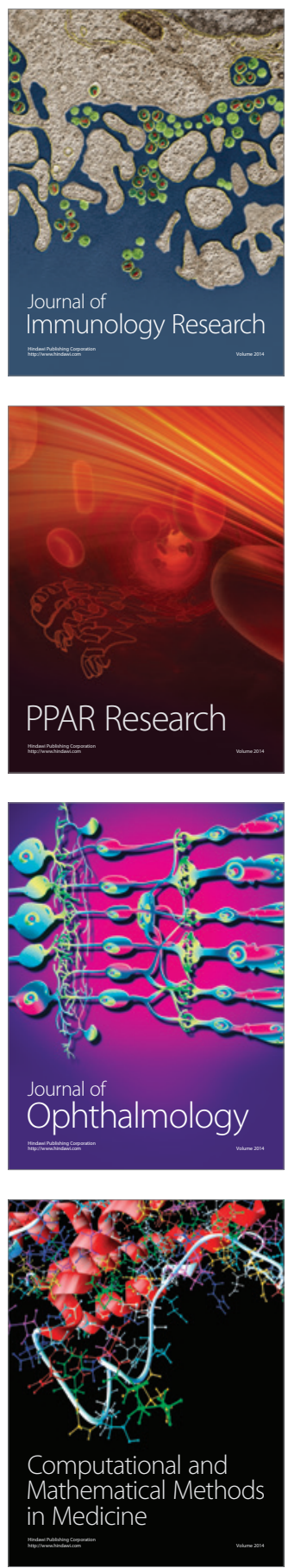

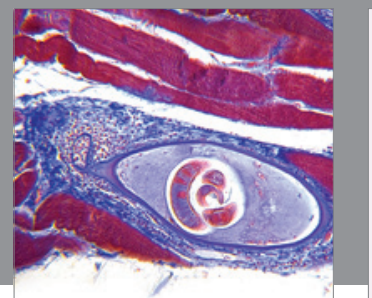

Gastroenterology

Research and Practice
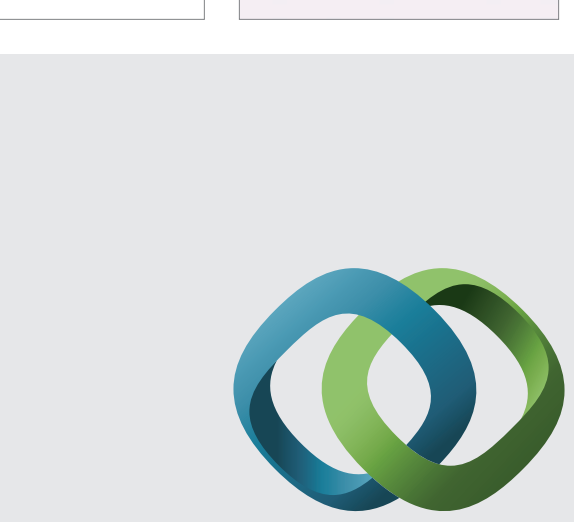

\section{Hindawi}

Submit your manuscripts at

http://www.hindawi.com
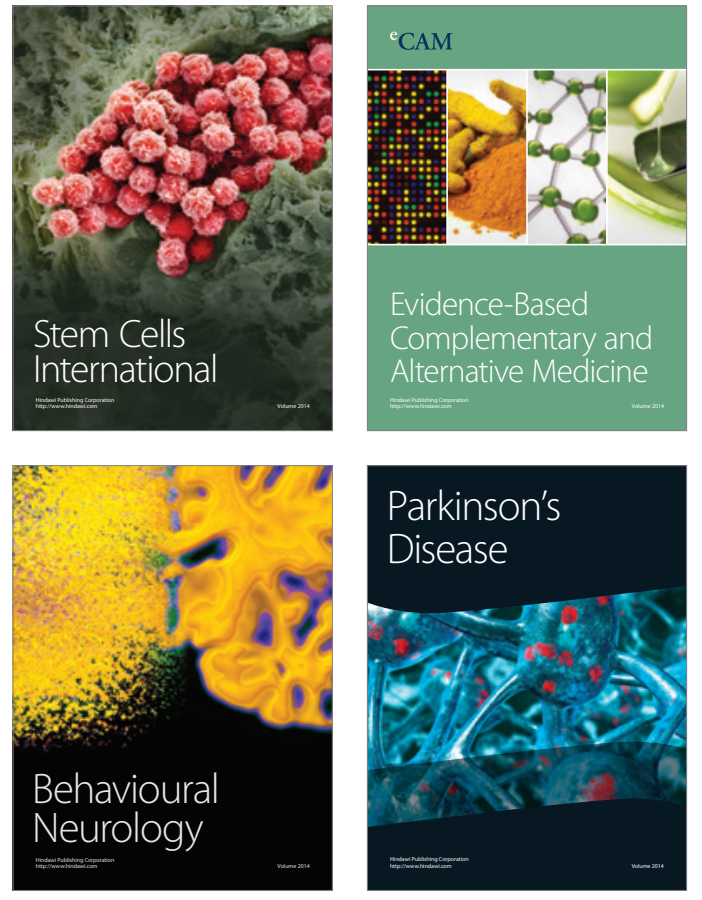
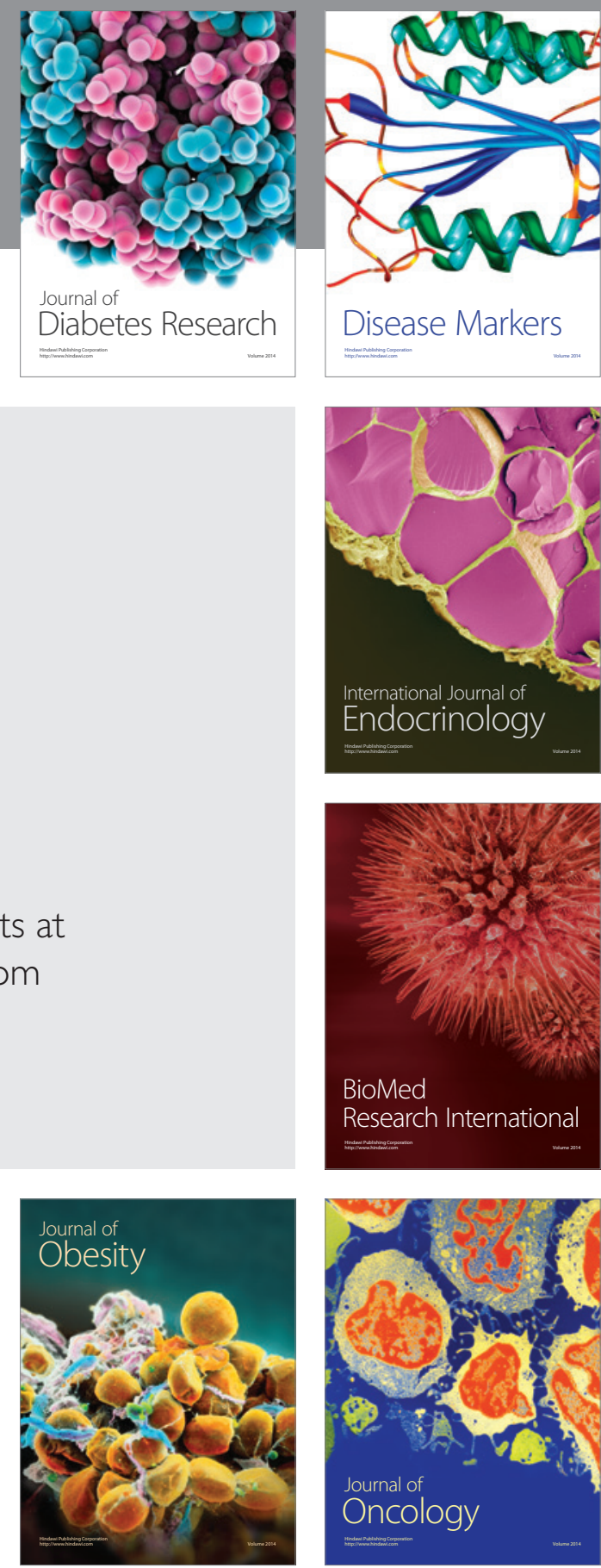

Disease Markers
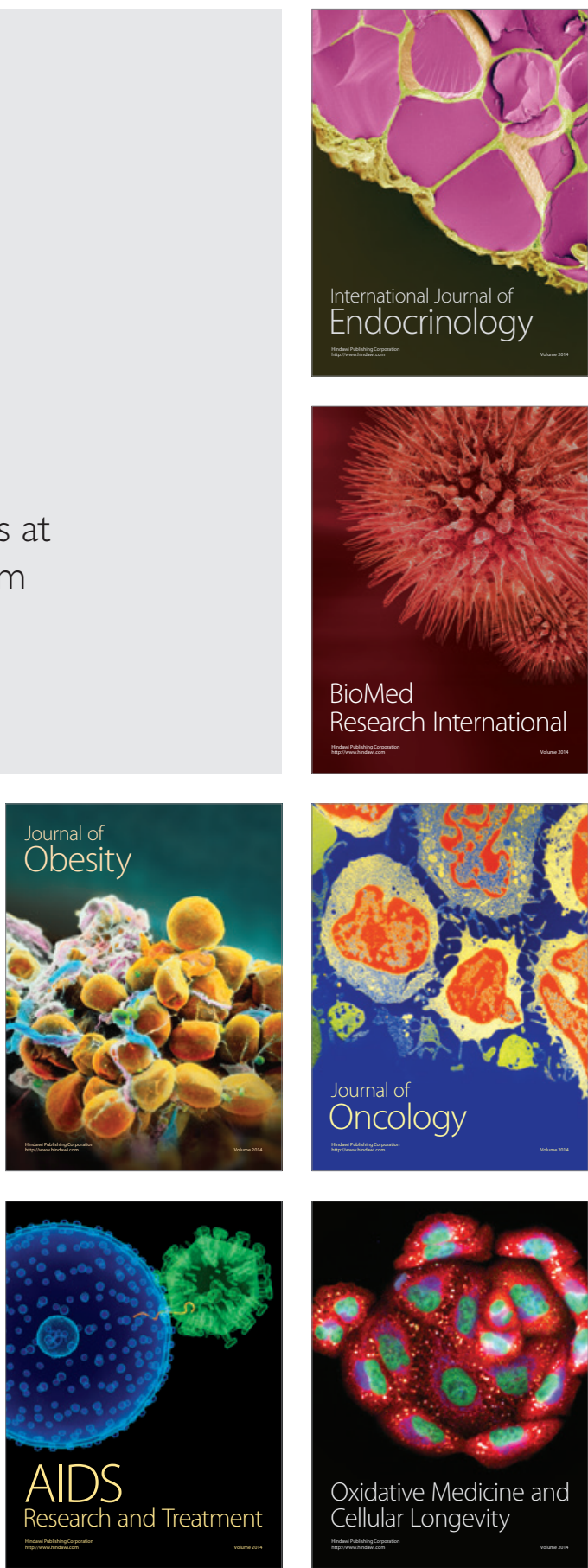